\title{
Papers
}

\section{Reducing the risk of major elective surgery: randomised controlled trial of preoperative optimisation of oxygen delivery}

Jonathan Wilson, Ian Woods, Jayne Fawcett, Rebecca Whall, Wendy Dibb, Chris Morris, Elizabeth McManus

\begin{abstract}
Objectives To determine whether preoperative optimisation of oxygen delivery improves outcome after major elective surgery, and to determine whether the inotropes, adrenaline and dopexamine, used to enhance oxygen delivery influence outcome. Design Randomised controlled trial with double blinding between inotrope groups.

Setting York District Hospital, England.

Subjects 138 patients undergoing major elective surgery who were at risk of developing postoperative complications either because of the surgery or the presence of coexistent medical conditions. Interventions Patients were randomised into three groups. Two groups received invasive haemodynamic monitoring, fluid, and either adrenaline or dopexamine to increase oxygen delivery. Inotropic support was continued during surgery and for at least 12 hours afterwards. The third group (control) received routine perioperative care.

Main outcome measures Hospital mortality and morbidity.

Results Overall, 3/92 (3\%) preoptimised patients died compared with $8 / 46$ controls $(17 \%)(\mathrm{P}=0.007)$. There were no differences in mortality between the treatment groups, but 14/46 (30\%) patients in the dopexamine group developed complications compared with 24/46 (52\%) patients in the adrenaline group (difference 22\%, 95\% confidence interval $2 \%$ to $41 \%$ ) and 28 patients $(61 \%)$ in the control group (31\%, 11\% to $50 \%)$. The use of dopexamine was associated with a decreased length of stay in hospital.

Conclusion Routine preoperative optimisation of patients undergoing major elective surgery would be a significant and cost effective improvement in perioperative care.

\section{Introduction}

Major elective surgery contributes to intensive care occupancy, with a significant mortality rate. ${ }^{2}$ In the United Kingdom most patients are taken from the general ward directly to the operating theatre before major elective surgery. The extent of perioperative monitoring is dependent on the anaesthetist, and the site of postoperative care will depend on the anticipated development of complications and the availability of intensive care beds or high dependency beds.

The enhancement of oxygen delivery to the tissues, guided by data obtained with pulmonary artery catheters, has been shown to improve outcome of patients deemed to be at high risk from major surgery. ${ }^{3}$

Oxygen delivery is dependent on the amount of oxygen in the blood and the cardiac index. Optimisation of cardiac index requires fluid and inotrope therapy to increase cardiac contractility. Inotropic agents, however, have different effects on circulation to the gut, which may possibly affect postoperative morbidity. ${ }^{5}$ Dopexamine (Dopacard, Ipsen, Maidenhead), is a peripheral vasodilator, which is associated with improved splanchnic oxygenation, ${ }^{67}$ whereas adrenaline (epinephrine), commonly used in intensive care, may reduce splanchnic flow. ${ }^{8}$

Our study compared the outcome in a population of elective surgical patients receiving either preoperative optimisation of oxygen delivery (treatment groups) or undergoing current hospital practice (control group). We also tested whether the inotrope dopexamine, given in a double blind fashion, affects outcome.

\section{Subjects and methods}

Approval for our study was obtained from the ethics committee of York District Hospital, and written consent was obtained from all the patients. We considered all patients undergoing major elective surgical procedures in general surgery, vascular surgery, and urology. Patients were identified as being at high risk of developing perioperative complications on the basis of either surgical criteria or the presence of coexisting medical conditions (table 1 ).

The care of control patients was determined by the individual surgeon and anaesthetist according to their routine practices for the operation. Generally, the patients remained on the general surgical ward until surgery and were then returned to either intensive care, high dependency care, or the ward postoperatively. No routine preoperative fluid protocol was followed for these patients.

\section{Editorial by Treasure and Bennett \\ Department of Anaesthetics, York District Hospital, York YO31 8HE Jonathan Wilson, consultant Ian Woods, consultant Intensive Care Unit, York District Hospital Jayne Fawcett, research nurse Rebecca Whall, research nurse Wendy Dibb, research nurse Chris Morris, research nurse \\ Pharmacy, York District Hospital Elizabeth McManus, senior pharmacist \\ Correspondence to: Dr Wilson jonathan@critbase. demon.co.uk}

BMJ 1999;318:1099-103

website extra

Details of the flow of patients through the trial appear on the BMJ's website

www.bmj.com 
Table 1 Age and admission criteria for patients undergoing major elective surgery. Values are number (percentage) unless stated otherwise

\begin{tabular}{lccc} 
Criteria & $\begin{array}{c}\text { Adrenaline group } \\
(\mathbf{n}=\mathbf{4 6})\end{array}$ & $\begin{array}{c}\text { Dopexamine } \\
\text { group } \mathbf{( n = 4 6 )}\end{array}$ & $\begin{array}{c}\text { Control group } \\
(\mathbf{n = 4 6 )}\end{array}$ \\
\hline Median age (years; interquartile range) & $71.5(64-77)$ & $70.0(65-74)$ & $71.5(65-76)$ \\
\hline Surgical admission criteria: & & & \\
\hline Repair of aortic or common iliac aneurysm & $14(30)$ & $15(33)$ & $13(28)$ \\
\hline $\begin{array}{l}\text { Planned resection of upper gastrointestinal } \\
\text { malignancy }\end{array}$ & $9(20)$ & $10(22)$ & $8(17)$ \\
\hline Anterior resection & $12(26)$ & $4(9)$ & $12(26)$ \\
\hline Cystectomy & $4(9)$ & $5(11)$ & $1(2)$ \\
\hline Medical criteria: & & & \\
\hline Ischaemic heart disease & $13(28)$ & $13(28)$ & $18(39)$ \\
\hline Myocardial infarction in past 5 years & $7(15)$ & $4(9)$ & $4(9)$ \\
\hline Congestive cardiac failure & $4(9)$ & $1(2)$ & $3(7)$ \\
\hline Cerebrovascular disease & $6(13)$ & $2(4)$ & $5(11)$ \\
\hline Hypertension & $18(39)$ & $11(24)$ & $15(33)$ \\
\hline Peripheral vascular disease & $4(9)$ & $3(7)$ & $2(4)$ \\
\hline Obstructive airways disease & $3(7)$ & $3(7)$ & $7(15)$ \\
\hline Pulmonary embolus & $0(0)$ & $1(2)$ & $0(0)$ \\
\hline Chronic renal insufficiency & $1(2)$ & $0(0)$ & $0(0)$ \\
\hline Diabetes mellitus with end organ damage & $1(2)$ & $0(0)$ & $6(13)$ \\
\hline Long term systemic steroid therapy & $2(4)$ & $4(9)$ & $2(4)$ \\
\hline Total No of patients with one or more & $34(74)$ & $30(65)$ & $34(74)$ \\
medical conditions ${ }^{*}$ & & & \\
\hline${ }^{*}$ P=0.57. & & &
\end{tabular}

Table 2 Haemodynamic and oxygen transport in inotrope groups only. Values are median (interquartile range) unless stated otherwise

\begin{tabular}{|c|c|c|}
\hline Variable & $\begin{array}{l}\text { Adrenaline group } \\
\qquad(\mathrm{n}=46)\end{array}$ & $\begin{array}{l}\text { Dopexamine group } \\
\qquad(\mathrm{n}=46)\end{array}$ \\
\hline \multicolumn{3}{|l|}{ Baseline: } \\
\hline Pulmonary artery occlusion pressure $(\mathrm{mm} \mathrm{Hg})$ & $12.0(9.0-15.0)$ & $10.0(8.0-12.0)$ \\
\hline Cardiac index $\left(\mathrm{ml} / \mathrm{min} / \mathrm{m}^{2}\right)$ & $3.2(2.6-3.6)$ & $3.6(2.9-4.1)$ \\
\hline Oxygen delivery $\left(\mathrm{ml} / \mathrm{min} / \mathrm{m}^{2}\right)$ & $530(435-590)$ & $564(486-636)$ \\
\hline \multicolumn{3}{|l|}{ End fluid optimisation phase: } \\
\hline Fluid given (ml) & $1250(1000-1500)$ & $1100(875-1300)$ \\
\hline Pulmonary artery occlusion pressure $(\mathrm{mm} \mathrm{Hg})$ & $14.0(13.0-15.0)$ & $13.5(12.0-15.0)$ \\
\hline Cardiac index & $3.5(2.8-4.0)$ & $3.8(3.3-4.5)$ \\
\hline Oxygen delivery & $541(438-590)$ & $604(521-686)$ \\
\hline \multicolumn{3}{|l|}{ End inotrope optimisation phase: } \\
\hline No of increments & 1.0 & 1.0 \\
\hline Pulmonary artery occlusion pressure $(\mathrm{mm} \mathrm{Hg})$ & $13.5(11.0-15.0)$ & $13.0(10.2-14.0)$ \\
\hline Cardiac index & $4.7(4.0-5.3)$ & $4.3(3.8-4.8)$ \\
\hline Oxygen delivery & $721(638-827)$ & $665(632-769)$ \\
\hline Total fluid given (ml) & $1500(1000-2000)$ & $1525(1000-2000)$ \\
\hline Duration of preoptimisation (minutes) & $276(200-345)$ & $275(214-331)$ \\
\hline No of patients who failed to reach target oxgen delivery & 1 & 3 \\
\hline No of patients with new dysrhythmias: & 4 & 1 \\
\hline Ventricular ectopics & 2 & 0 \\
\hline Ventricular tachycardia & 0 & 1 \\
\hline Sinus tachycardia & 2 & 0 \\
\hline \multicolumn{3}{|l|}{ Additional therapy: } \\
\hline Blood transfusion & 2 & 2 \\
\hline Oxygen therapy & 8 & 5 \\
\hline
\end{tabular}

Patients in the adrenaline group and dopexamine group were admitted to either intensive care or high dependency care a minimum of 4 hours before surgery. A large intravenous cannula was inserted in the patient's forearm and an intra-arterial cannula was placed in the patient's radial artery for measurement of blood pressure and for blood sampling. A pulmonary artery catheter enabling continuous measurement of cardiac index (Baxter Swan Ganz IntelliCath, Baxter Healthcare, Irvine, CA) was inserted via a central vein. All line insertions were carried out under local anaesthesia, with sedation where required.
Oxygen delivery was measured using the standard formula: oxygen delivery $\left(\mathrm{ml} / \mathrm{min} / \mathrm{m}^{2}\right)=$ cardiac index $\left(1 / \mathrm{min} / \mathrm{m}^{2}\right) \times$ oxygen content of blood (haemoglobin $(\mathrm{g} / \mathrm{l}) \times$ oxygen saturation $\times 1.34)$.

Optimisation of oxygen delivery consisted of two phases: fluid optimisation and inotrope optimisation.

Fluid optimisation-All patients received 1 litre of Hartmann's solution during line insertion. Human albumin solution $4.5 \%$ was then infused until a pulmonary artery occlusion pressure of $12 \mathrm{~mm} \mathrm{Hg}$ was achieved. If haemoglobin concentration was $<110 \mathrm{~g} / \mathrm{l}$, red blood cells were transfused instead of the albumin solution. If oxygen saturation was $<94 \%$, supplemental oxygen was provided.

Inotrope optimisation-Inotrope was commenced at a rate ( $\mathrm{ml} /$ hour) calculated from a chart according to the patient's weight and equated to $0.025 \mu \mathrm{g} / \mathrm{kg} / \mathrm{min}$ for adrenaline and $0.125 \mu \mathrm{g} / \mathrm{kg} / \mathrm{min}$ for dopexamine. Blinding was achieved by administering the inotrope in a syringe that had been preprepared in the pharmacy. The infusion was increased by single multiples of the initial rate until the target oxygen delivery of $>600 \mathrm{ml} / \mathrm{min} / \mathrm{m}^{2}$ was achieved or the onset of side effects was noted (increase in heart rate $>30 \%$ above baseline or development of chest pain or a new dysrhythmia). If side effects were noted, the infusion was decreased. All patients were started on the study inotrope even if the target oxygen delivery had been achieved after the fluid phase. The infusion was maintained at the preoperative rate throughout the remainder of the perioperative period.

Intraoperative care was the responsibility of the anaesthetist, including provision of additional inotropes if thought necessary.

After surgery, patients were returned to intensive care or high dependency care. The study inotrope was continued at the preoperative rate for 12 to 24 hours postoperatively. The time of discontinuation of the inotrope was at the discretion of the intensive care team. On a routine clinical basis the intensive care and surgical teams determined all other aspects of care including removal of the pulmonary artery catheter and timing of discharge from intensive care or high dependency care.

\section{Statistical analysis}

We required 46 patients in each group, calculated by matching reductions in mortality from $25 \%$ to $5 \%$ from the most similar previous study, to give a study power of $80 \% .^{4}$ The randomisaton sequence was generated from a Unix computer program. Allocation was concealed until trial entry by sealed opaque envelope. Randomisation was stratified into three subgroups: vascular surgery, surgery for upper gastrointestinal malignancy, and others. This was to ensure even distribution of these surgical subgroups across the three groups.

\section{Outcome measures}

Primary outcome measures were hospital mortality and morbidity (number of patients developing one or more of a predefined range of complications). Secondary measures were length of stay in hospital, use of intensive care or high dependency care, and haemodynamic measurements (for adrenaline and dopexamine groups). We analysed hospital mortality by Kaplan- 
Meier survival estimates, using the log-rank test for comparison, and by Fisher's exact test. The differences in proportions of patients with morbidity were calculated. Standardised ratios were constructed for morbidity and mortality, comparing actual incidences to those predicted by the POSSUM score (physiologi$\mathrm{cal}$ and operative severity score for the enumeration of mortality and morbidity). ${ }^{9}$ Where appropriate, we calculated $95 \%$ confidence intervals. ${ }^{10}$ Kaplan-Meier estimates were constructed for hospital length of stay, treating non-survivors as censored values, and analysed using the log-rank test.

Analysis was on an intention to treat basis.

\section{Results}

Overall, 203 patients were identified and approached over a 16 month period; 65 did not enter the study either because of refusal to consent (40), lack of intensive care or high dependency care beds (16), or other reasons (9) (see website).

Table 1 shows the entry criteria for each group.

Table 2 outlines the variables for haemodynamics and oxygen transport obtained at the key stages of preoperative optimisation. One patient in the adrena-

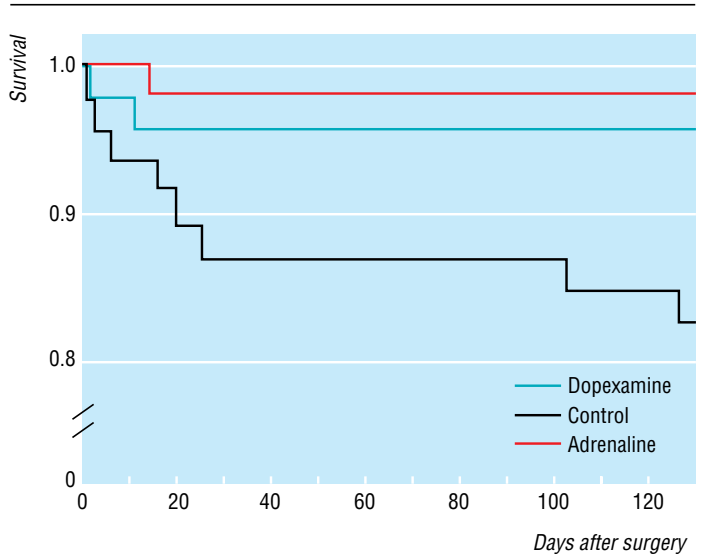

Fig 1 Survival after surgery (proportion of original study population)

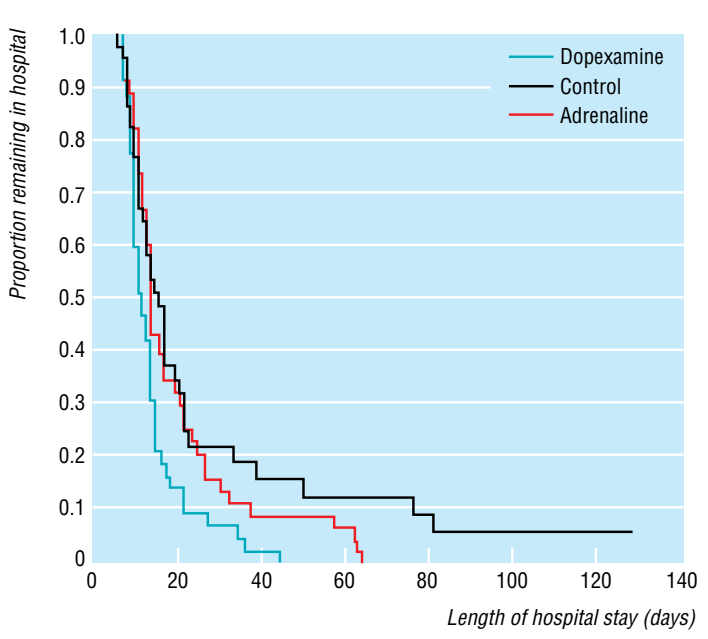

Fig 2 Length of stay in hospital after surgery (proportion of original study population)
Table 3 Mortality data for patients receiving inotrope or standard hospital practice

\begin{tabular}{lccc} 
& $\begin{array}{c}\text { Adrenaline group } \\
(\mathbf{n}=\mathbf{4 6 )}\end{array}$ & $\begin{array}{c}\text { Dopexamine group } \\
(\mathbf{n = 4 6 )}\end{array}$ & $\begin{array}{c}\text { Control group } \\
(\mathbf{n}=\mathbf{4 6})\end{array}$ \\
\hline No of patients surviving & 45 & 44 & 38 \\
\hline Hospital survival $(\% ; 95 \% \mathrm{Cl})$ & $98(94$ to 100$)$ & $96(90$ to 100$)$ & $83(72$ to 94$)$ \\
\hline & \multicolumn{2}{c}{ Combined treatment groups: $97(93 \text { to } 100)^{*}$} \\
\hline Actual mortality $(\%)$ & 2 & 4 & 17 \\
\hline Predicted mortality $(\%)$ & 12 & 15 & 13 \\
\hline Standardised mortality ratio $(95 \% \mathrm{Cl})$ & $0.19(0.00$ to 1.05$)$ & $0.28(0.04$ to 1.08$)$ & $1.36(0.6$ to 2.75$)$ \\
\hline *Fisher's test for combined treatment groups $v$ control, $\mathrm{P}=0.007$ &
\end{tabular}

Table 4 Morbidity data for patients receiving inotrope or standard hospital practice

\begin{tabular}{|c|c|c|c|}
\hline Variable & $\begin{array}{l}\text { Adrenaline group } \\
\qquad(\mathrm{n}=46)\end{array}$ & $\begin{array}{l}\text { Dopexamine group } \\
(\mathrm{n}=46)\end{array}$ & $\begin{array}{l}\text { Control group } \\
(n=46)\end{array}$ \\
\hline \multicolumn{4}{|l|}{ Respiratory: } \\
\hline Prolonged weaning & 1 & 3 & 1 \\
\hline Adult respiratory distress syndrome & 1 & 1 & 4 \\
\hline Pleural effusion & 3 & 3 & 2 \\
\hline Secondary ventilation & 6 & 4 & 8 \\
\hline Sputum retention & 4 & 1 & 5 \\
\hline \multicolumn{4}{|l|}{ Cardiovascular: } \\
\hline Myocardial infarction & 4 & 2 & 3 \\
\hline New arrhythmia & 8 & 7 & 11 \\
\hline Cardiac arrest & 1 & 1 & 3 \\
\hline Pulmonary embolus & 1 & 1 & 2 \\
\hline Cerebrovascular accident & 0 & 0 & 1 \\
\hline Transient ischaemic attack & 1 & 0 & 0 \\
\hline Cardiac failure & 14 & 4 & 12 \\
\hline \multicolumn{4}{|l|}{ Gastrointestinal: } \\
\hline Infarction of gastrointestinal tract & 1 & 0 & 1 \\
\hline Gastrointestinal haemorrhage & 0 & 0 & 4 \\
\hline Renal or metabolic: Acute renal failure & 2 & 0 & 3 \\
\hline Haematological or immune: Coagulopathy & 2 & 1 & 4 \\
\hline \multicolumn{4}{|l|}{ Infection: } \\
\hline Bacteraemia & 2 & 0 & 2 \\
\hline Sepsis syndrome & 2 & 0 & 1 \\
\hline Septic shock & 0 & 2 & 0 \\
\hline Respiratory sepsis & 8 & 2 & 7 \\
\hline Urinary sepsis & 0 & 1 & 5 \\
\hline Abdominal sepsis & 2 & 0 & 2 \\
\hline Wound sepsis & 3 & 0 & 3 \\
\hline Line sepsis & 0 & 1 & 0 \\
\hline Other sepsis & 5 & 0 & 2 \\
\hline \multicolumn{4}{|l|}{ Surgical: } \\
\hline Anastomotic breakdown & 0 & 0 & 3 \\
\hline Deep haemorrhage & 2 & 2 & 4 \\
\hline Wound haemorrhage & 3 & 0 & 2 \\
\hline Total & 87 & 44 & 109 \\
\hline No of patients with complications & 24 & 14 & 28 \\
\hline Proportion of patients & 0.52 & 0.30 & 0.61 \\
\hline \multicolumn{4}{|c|}{ Differences in proportions of patients with complications $(95 \% \mathrm{CI})$ : } \\
\hline Dopexamine $v$ control & & $0.30(0.11$ to 0.50$)$ & \\
\hline Dopexamine $v$ adrenaline & & $0.21(0.02$ to 0.41$)$ & \\
\hline Adrenaline $v$ control & & $0.09(-0.11$ to 0.28$)$ & \\
\hline Actual morbidity (\%) & 52 & 30 & 61 \\
\hline Predicted morbidity (\%) & 54 & 61 & 57 \\
\hline Standardised morbidity ratio $(95 \% \mathrm{Cl})$ & $0.96(0.62$ to 1.44$)$ & $0.50(0.27$ to 0.84$)$ & $1.07(0.71$ to 1.54$)$ \\
\hline
\end{tabular}

line group and three patients in the dopexamine group failed to reach target oxygen delivery owing to the development of side effects.

According to the POSSUM scores, there were no differences in operative risk. One patient in the adrenaline group returned from theatre to the ward because of an inoperable lesion. One patient in the dopexamine group pulled out his pulmonary artery catheter immediately before surgery because he was confused. All other patients completed the minimum 
Table 5 Perioperative data for patients receiving inotrope or standard hospital practice. Values are median (interquartile range) unless stated otherwise

\begin{tabular}{|c|c|c|c|}
\hline Variable & $\begin{array}{l}\text { Adrenaline } \\
\text { group }(n=46)\end{array}$ & $\begin{array}{l}\text { Dopexamine } \\
\text { group }(n=46)\end{array}$ & $\begin{array}{c}\text { Control } \\
\text { group }(n=46)\end{array}$ \\
\hline \multicolumn{4}{|l|}{ Surgery type (No of patients): } \\
\hline Aortic surgery & 14 & 15 & 13 \\
\hline Upper gastrointestingal malignancy & 9 & 10 & 8 \\
\hline Other & 23 & 21 & 25 \\
\hline \multicolumn{4}{|l|}{ Anaesthetic data: } \\
\hline Operation length (minutes) & $135(75-190)$ & $130(78-315)$ & $116(70-145)$ \\
\hline General anaesthesia only (No of patients) & 8 & 14 & 11 \\
\hline General anaesthesia and epidural block (No of patients) & 38 & 32 & 35 \\
\hline Total fluid given (ml) & $\begin{array}{c}3025 \\
(2000-4000)\end{array}$ & $\begin{array}{c}3375 \\
(2200-4500)\end{array}$ & $\begin{array}{c}3500 \\
(2500-4000)\end{array}$ \\
\hline Additional inotropes in theatre (No of patients) & 15 & 5 & 18 \\
\hline \multicolumn{4}{|l|}{ POSSUM score: } \\
\hline Physiological component & $20(17-24)$ & $20(16-24)$ & $20(16-24)$ \\
\hline Operative component & $15(11-20)$ & $17(13-20)$ & $16(12-17)$ \\
\hline Total & $35(32-39)$ & $37(31-41)$ & $36(32-39)$ \\
\hline \multicolumn{4}{|l|}{ Postoperative location (No of patients): } \\
\hline Intensive care unit & 19 & 16 & 18 \\
\hline High dependency unit & 26 & 30 & 12 \\
\hline General ward & 1 & 0 & 16 \\
\hline No intensive care or high dependency care & 0 & 0 & 14 \\
\hline \multicolumn{4}{|l|}{ Bed usage (days): } \\
\hline Total hospital bed use for group & 875 & 596 & 1008 \\
\hline Intensive care unit or high dependency unit (No of patients) & $192(46)$ & $152(46)$ & $176(32)$ \\
\hline Intensive care unit or high dependency unit per patient & 4.2 & 3.3 & 5.5 \\
\hline Per patient & 19 & 13 & 22 \\
\hline
\end{tabular}

requirement of 12 hours' infusion of study inotrope postoperatively.

Overall, preoperative optimisation of oxygen delivery significantly reduced hospital mortality; 3/92 (3\%) patients who were preoptimised died compared with $8 / 46$ controls $(17 \%, P=0.007$; table 3$)$. Compared with both the control and the adrenaline group, there was a significant reduction in morbidity in the dopexamine group (table 4). Optimisation with adrenaline alone did not significantly reduce morbidity compared with control. Compared with the value predicted from the POSSUM score, dopexamine is associated with a significantly reduced incidence of morbidity.

The length of hospital stay for the dopexamine group was significantly reduced when individually compared with both the adrenaline group $(\mathrm{P}=0.02)$ and the control group $(\mathrm{P}=0.009)$. There was no overall increase in intensive care resources or high dependency care resources in the treated groups compared with control, although only $32 / 46(70 \%)$ of control patients were admitted to these areas at any time during their hospital stay.

\section{Discussion}

Our study is a pragmatic one of the effect of a package of preoperative interventions on the outcome from major elective surgery in a typical UK hospital. The package comprises several components, each of which may have contributed to improvements in outcome.

\section{Surgical risk}

The criteria for patient selection were as a result of reviewing the elective surgical population for intensive care or high dependency care in our own hospital; outcome of control patients would seem to justify their use. We were unable to effect true blinding between patients in the control and treatment groups, but we have no evidence to suggest that this may have biased our results. The POSSUM scoring system was specifically developed for, and validated in, a UK general surgical population and can be used to explain differences in surgical outcome on the basis of different risk. ${ }^{912} 13$ The range of surgical procedures and POSSUM scores for surgical risk would suggest that the three groups were evenly balanced. The hospital mortality of $17 \%$ in the control group seems high, but two late deaths contributed to this value (fig 1). POSSUM was derived from data recorded for 6 weeks postoperatively; at that time our control group mortality was $13 \%$ - exactly that predicted by POSSUM. After major surgery a proportion of patients will still be in hospital at 6 weeks (fig 2) and, because of the serious morbidity delaying discharge, are likely to have significant mortality.

Use of intensive care beds or high dependency beds-Sixteen control patients went back to the general ward after surgery (table 5). The location of postoperative care was the decision of the clinical team responsible for the patient, and no patient was denied access to intensive care or high dependency care owing to lack of beds. The improvements we have shown, however, can also be observed in study populations consisting exclusively of patients in intensive care. ${ }^{34}$

Oxygen delivery as a goal-High risk surgery is one of the few areas in which reasonable evidence now exists of the benefits of optimising oxygen delivery. When oxygen delivery falls below $390 \mathrm{l} / \mathrm{min} / \mathrm{m}^{2}$, tissue oxygenation becomes physiologically inadequate in surgical patients at high risk. ${ }^{14}$ This is a reduction of just 30\% from the median baseline measurements for oxygen delivery in our study groups. Because of blood loss during surgery, reductions in haemoglobin concentration and cardiac output are common occurrences in patients who are not monitored, with consequent falls in tissue oxygenation and the increased likelihood of complications.

\section{Fluid optimisation}

Intraoperative fluid requirements were the same in all groups. The treatment groups, however, received an average of $1500 \mathrm{ml}$ of additional fluid preoperatively, on the basis of measurements from the pulmonary artery catheter. Considerable evidence exists that provision of optimal fluid improves outcome after surgery. ${ }^{3} 4111516$ All of these studies, however, used additional "nonroutine" monitoring to estimate fluid requirements; it is therefore implicit that routine, less invasive monitoring may leave patients relatively depleted of fluid and at higher risk of adverse outcomes. Because of the low doses of inotropes used in our study, we suggest that fluid optimisation is the major contributor to improved oxygen delivery in our patients.

\section{Choice of inotrope}

Both inotropes produced the desired preoperative increase in oxygen delivery and a similar decrease in mortality. Only dopexamine, however, reduced morbidity and hospital stay. Although POSSUM scores were equal, there is a suggestion that the patients who received dopexamine may have had less pre-existing cardiovascular disease and a higher baseline oxygen delivery. In the dopexamine group, however, there was a reduction in infective complications. Dopexamine 
Key messages

- Major elective surgery in UK general hospitals still carries significant mortality and morbidity

- Preoperative administration of fluid and inotropes, guided by invasive monitoring, can significantly reduce mortality, morbidity, and length of hospital stay

- The choice of inotrope may influence the extent of improvements in outcome

- Routine preoperative optimisation would require initial investment in high dependency care facilities but is likely to be cost effective by reducing complications and length of hospital stay

has significant anti-inflammatory properties, reducing the release of toxic mediators in response to an infective challenge. ${ }^{17}$ This contrasts with the effects of inotropes with $\alpha 1$ receptor activity such as adrenaline. ${ }^{18}$ Thus dopexamine may confer an additional advantage to fluid optimisation by reducing the effect of infective complications.

\section{Conclusion}

The incidence of morbidity in our control group suggests that there is a substantial population of surgical patients in the United Kingdom who are likely to benefit from the interventions described. Only $5 \%$ of all planned elective surgical admissions to intensive care are currently admitted preoperatively. ${ }^{2}$ Formal cost benefit analysis was not performed in this study, but values for usage of intensive carebeds or high dependency care beds (table 5) and length of stay in hospital suggest there may be overall savings in hospital costs when preoptimising patients for major elective surgery. An initial investment in resources may lead to economic gains for hospitals as well as a better outcome for surgical patients.

We thank the patients, their surgeons, and the medical and nursing staff of the intensive care, anaesthetic, and operating theatre departments for their patience and cooperation. Andy Vale, senior medical statistician at the University of Leeds, gave advice on statistical analysis.
Contributors: JW and IW were responsible for the original concept of the study. JW analysed the data; he will act as guarantor for the paper. All authors were involved with the design and execution of the study and with writing the paper.

Funding: Grant of $£ 45000$ from the National Hospital Lotteries Fund.

Competing interests: York District Hospital's intensive care unit research fund was reimbursed by Ipsen, the manufacture of dopexamine, after RJTW and IW spoke at meetings arranged by Ipsen.

1 Campling EA, Devlin HB, Hoile RW, Lunn JN. National Confidentia Enquiry into Perioperative Deaths. London: Royal College of Surgeons, 1992.

2 Intensive Care National Audit and Research Centre. Annual report from the national case mix programme database. London: Intensive Care National Audit and Research Centre, 1998.

3 Shoemaker WC, Appel PL, Kram HB, Waxman K, Lee T. Prospective trial of supranormal values of survivors as therapeutic goals in high-risk surgical patients. Chest 1987;94:1176-86.

4 Boyd O, Grounds RM, Bennett ED. A randomised clinical trial of the effect of deliberate perioperative increase of oxygen delivery on mortality in high-risk surgical patients. JAMA 1993;270:2699-707.

5 Mythen MG, Webb AR. The role of gut mucosal hypoperfusion in the pathogenesis of post-operative organ dysfunction. Intensive Care Med 1994;20:203-9.

6 Brown RA, Dixon J, Farmer JB, Hall JC, Humphries RG, Ince F, et al. Dopexamine: a novel agonist at peripheral dopamine receptors and B-receptors. Br J Pharm 1985;85:599-608.

7 Smithies M, Yee TH, Jackson L, Beale R, Bihari D. Protecting the gut and the liver in the critically ill: effects of dopexamine. Crit Care Med 1994;22:789-95.

8 Meier-Hellmann A, Reinhart K, Bredle DL, Specht M, Spies CD, Hannemann L. Adrenaline impairs splanchnic perfusion in septic shock. Crit Care Med 1997;25:399-404

9 Copeland GP, Jones MW. POSSUM: a scoring system for surgical audit Br J Surg 1991;78:355-60.

10 Gardner MJ, Altman DG. Statistics with confidence. London: BMJ Books, 1989

11 Berlauk JF, Abrams JH, Gilmore IJ, O'Conner SR, Knighton DR, Cerr FB. Preoperative optimisation of cardiovascular hemodynamics improves outcome in peripheral vascular surgery. Ann Surg 1991;214:289-97.

12 Copeland GP, Jones D, Wilcox A, Harris PL. Comparative vascular audit using the POSSUM scoring system. Ann R Coll Surg Engl 1993;75:175-7.

13 Sagar PM, Hartley MN, Mancey-Jones B, Sedman PC, May J, Macfie J Comparative audit of colorectal resection with the POSSUM scoring system. Br J Surg 1994;81:1492-4.

14 Lugo G, Arizpe D, Dominguez G, Ramirez M, Tamariz O. Relationship between oxygen consumption and oxygen delivery during anesthesia in high-risk surgical patients. Crit Care Med 1993;21:64-9.

15 Sinclair S, James S, Singer M. Intraoperative intravascular volume optimisation and length of stay after repair of proximal femoral fracture: randomised controlled trial. BMJ 1997;315:909-12.

16 Mythen MG, Webb AR. Peroperative plasma volume expansion reduces the incidence of gut mucosal hypoperfusion in cardiac surgery. Arch Surg 1995; 130:423-9.

17 Erkens U, Scholz SE, Cordes T, Petzinger E, Hemplemann G. Dopexamine impairs hepatic cytokine secretion after stimulation by endotoxin via $\beta$-receptor. Intensive Care Med 1998;24:428S.

18 Tighe D, Moss R, Bennett ED. Adrenergic receptor $\alpha 1$ agonist and $\beta 2$ antagonist increase hepatic injury during sepsis. Intensive Care Med $1998 ; 24: 397 \mathrm{~S}$

(Accepted 18 February 1999)

\section{One hundred years ago \\ Mark Twain on Christian Science}

Mark Twain has fallen among the Christian Scientists, and relates his experiences in the October number of The Cosmopolitan. Last summer, on his way back to Vienna from the Appetite Cure in the mountains, he fell over a cliff and "broke some arms and legs and one thing and another." He was taken to a neighbouring village, where there was no surgeon. There happened, however, to be a lady from Boston, who was a Christian Science doctor, and could cure anything. So she was sent for. But the shades of night were falling, and she could not conveniently come; she sent word, however, that it did not in the least matter, as she would apply "absent treatment" and call in the morning. In the meantime the sufferer was bidden to make himself tranquil and comfortable, and remember there was nothing the matter with him. The patient was in some doubt whether the diagnosis had been made with sufficient care, but he tried to make himself believe that his pain was a delusion. Morning brought the Christian Scientist, who declined even to listen to the recital of his symptoms, assuring him that there is no such thing as feeling, and that nothing exists but mind, which cannot feel pain. "You should never," said she, "allow yourself to speak of how you feel, nor permit others to ask you how you are feeling; you should never concede that you are ill; nor permit others to talk about disease, or pain, or death, or similar non-existences in your presence. Such talk only encourages the mind to continue its empty imaginings." On the unfortunate sufferer pleading that he was full of imaginary tortures, which could not make him more uncomfortable if they were real, and asking what he could do to get rid of them, he was told that there was no occasion to get rid of them since they did not exist, but were mere illusions propagated by matter which itself had no existence. (BMJ 1899;ii:1123) 